\title{
PLANNING AND ADAPTING PRIMARY SOURCE MATERIALS FOR USE IN STATE AND LOCAL HISTORY STUDIES
}

\author{
Andrea Cantrell \\ University of Arkansas
}

1. Start with issues of immediate interest to the students. Expand each issue to a more general subject that relates to your established curriculum for the course. For example, one popular interest for some young people is antique cars. This interest could be expanded in several different directions--the development of state highways and their impact on the local economy. Another example--start with what students had for lunch today, how does the menu compare with school lunches of fifty years ago? This could lead to a study of changes in production and marketing of food products. Perhaps students whose attention seems centered on dating can be interested in changes in courtship and marriage customs.

2. Prepare a list of issues and expanded subjects for which you believe primary source materials would be appropriate and useful.

3. Three methods for identifying and obtaining reproductions of primary source materials are generally used:

a. Teachers select and arrange for reproductions directly with a library, archives, or museum.

b. Teachers obtain archival packs from state agencies, associations, institutions, or commercial publishers.

c. All or several students in the class are assigned the task of locating a primary source item. Students should be cautioned about obtaining permissions, careful use of originals, and how to use libraries.

4. Survey resources available to you, for both primary and secondary sources. Places to check include, but should not be limited to:
a. your school library;
b. community or county public library;
c. college or university libraries in the area;
d. city or county historical society;
e. area museum;
f. local genealogical society;
g. resource persons in the community;
h. state library and state historical society;
i. others listed in directories of libraries, archives, museums, and organizations. 
5. After identifying possible repositories of source materials, call or write the institutions most likely to have pertinent materials. Explain what you have in mind and inquire about their holdings and procedures. Arrange a visit.

6. Visit the repository you have selected. Be prepared to be asked to follow special procedures that have been developed to protect the materials, for example:

a. using pencil only (accidental ink smudges can seriously damage materials);

b. leaving all personal belongings, especially briefcases, purses, sacks, or other containers in lockers or separate shelves;

c. filling out application or request forms for access to materials;

d. keeping records in the exact order in which they are brought to you;

e. slow, careful handling of materials to avoid damaging them;

f. limitations on photocopying of fragile documents;

g. limitations on group use.

7. Explain to the librarian, archivist, or curator the kinds of materials you hope to find and the subjects you plan to cover. Often they can suggest good items. Be prepared, however, for the process of identifying materials to take time. Many collections have never been indexed or had extensive finding aids prepared. For your first project, keep expectations realistic.

8. Decide how the materials will be made available to students, for example:
a. photocopies;
b. transcriptions;
c. facsimiles;
d. photographs (prints or slides);
e. transparencies;
f. microfilm;
g. carefully planned onsite use of originals by students.

9. However you decide to make the materials available to the students, make arrangements with the library, archives, or museum staff as far in advance as possible. Two weeks or longer may be required for preparation of photographs or photocopies after you have selected the ones you wish to use.

10. If the institution is agreeable and you decide that group or individual onsite visits by students will be used:

a. Make arrangements as far in advance as possible and verify the date and time just before your visit.

b. Consider separating the class into small groups of several visits.

c. Assure proper supervision--I usually suggest one adult leader per six to ten students. 
d. Prepare students ahead of time with assignments for which you know relevant materials will be available. Students should know basic research skills and should have read background information.

e. Be sure that students know and will follow the institution's policies and procedures.

f. Especially stress the need for great care in using materials and in not disturbing other researchers.

11. Enjoy the excitement while your students make discoveries in records of the past!! 